\title{
Calibration of a method for selecting roundabouts as a function of the inner island treatment
}

\author{
J. Falciani ${ }^{1}$, A. Pratelli ${ }^{1}$, M. Martello ${ }^{2} \&$ R. Souleyrette ${ }^{2}$ \\ ${ }^{1}$ Department of Civil Engineering, University of Pisa, Italy \\ ${ }^{2}$ Department of Civil, Construction, and Environmental Engineering, \\ Iowa State University, United States
}

\begin{abstract}
It is generally accepted that a driver's ability to perceive, recognize, and react to surroundings contributes to safer roads. The objective of this paper is to investigate the perceptibility of roundabouts as influenced by their most distinctive feature - the central island treatment. Previous work has shown how visual perception of central island treatment can improve road safety performance. Recently, the authors have suggested a roundabout central island treatment classification scheme with three categories: Reduced, Compressed and Slender. Classifying roundabout central island treatment types was necessarily somewhat subjective. This paper introduces a more quantitative measure for central island visual perception, based on the theory of visual intrusion as measured by the solid angle subtending the central island treatment. Data were collected using laser instruments, Google Streetview ${ }^{\circledR}$ and Google Earth ${ }^{\circledR}$, and the related solid angles have been estimated for a large sample of roundabouts located both in Tuscany (Italy) and in the United States. The classification scheme is analyzed using the nonparametric Fisher's exact test which shows the central island treatment classification scheme is not associated with roundabout size. Therefore, central island treatment can be utilized as a unique metric for categorizing roundabouts. Descriptive statistics indicate that roundabouts with compressed island treatments have the largest solid angles (and implied visibility) when compared to either reduced or slender treatments, which have similar levels of visual intrusion as estimated by their solid angle.
\end{abstract}

Keywords: roundabout, central island treatment classification, solid angle. 


\section{Introduction}

The subject of this paper is the calibration of a model for the classification of roundabouts as a function of their central island treatment type by incorporating the idea of the "visual intrusion" of a roundabout central island as a positive design attribute by which to measure the perceptibility or visibility of the roundabout [2].

A goal of the paper is to quantify the level of roundabout perceptibility through the estimation of the central island treatment's "solid angle" [3]. The solid angle (on an approach) is a function of the surface area of the island treatment facing the driver and the distance the driver is from the island. Forty roundabouts located near the cities of Pisa, Livorno and Grosseto, Italy and 45 from the U.S. are analyzed.

\section{Roundabout visibility}

Two distinct issues of visibility for drivers approaching and entering or exiting a roundabout can be identified as:

- Unobstructed line-of-sight, for:

a) pedestrians

b) vehicles

- Perception/Recognition/"Readability" of the roundabout.

The unobstructed line-of-sight issue is critical for approaching traffic to be able to yield to pedestrians and vehicles appropriately and to select adequate gaps before entering the circulatory roadway and then to safely exit from the roundabout.

However, there are other visibility issues related to the "readability" of the intersection, understood here as the perceptibility of the roundabout by drivers through the recognition of its major components, such as the central islands. The treatment of the central inner island is important for perception, recognition, and "reading" at a distance upstream of the roundabout [1].

\subsection{Visual intrusion}

The term "visual intrusion" is used to indicate the effects on aesthetics that a generic transport structure has on the surrounding environment [3]. The term "transport structure" implies the physical structure as well as the traffic that uses it. This definition does not necessarily imply a negative; in fact, "visual intrusion" can be helpful to drivers.

In the case of the roundabout, the "transport structure" analyzed in this paper, the element that might or might not improve driver perception of the roundabout is the central island, particularly in its design or treatment (what is placed on the central island) [2]. The phenomenon of visual intrusion is assessed by measuring the solid angle and the solid angle can be defined as the portion of the surface of a sphere which covers a particular object, as seen by an observer in the center of 
the sphere [4]. For a small region of area A, the numerical value of the solid angle $\Omega$ can be estimated by:

$$
\Omega=\mathrm{A} / \mathrm{R}^{2}
$$

where $\mathrm{A}$ is the surface area of the element that characterizes the central island (tree, vegetation, mast, memorial, etc.) perceived by a driver who is approaching the roundabout. $\mathrm{R}$ is the distance between the driver and the central island element, and for this study is taken as the distance from the driver to the central island treatment at a distance of 15 meters from the circulating roadway outer delineating pavement markings. This is also the minimum safe distance for a clear perception of the roundabout, in accordance with Italian guidelines for yield intersections [5].

\subsection{Treatment of the central island}

Three basic central island treatment types are described below [2].

a) Reduced treatment: "Reduced" means a treatment of content spread and diffused over the whole surface of the inner island. Treatments of this type could include a hill with simple lawn, or lawn adorned with seasonal flowers and/or low bushes. See Figure 1.

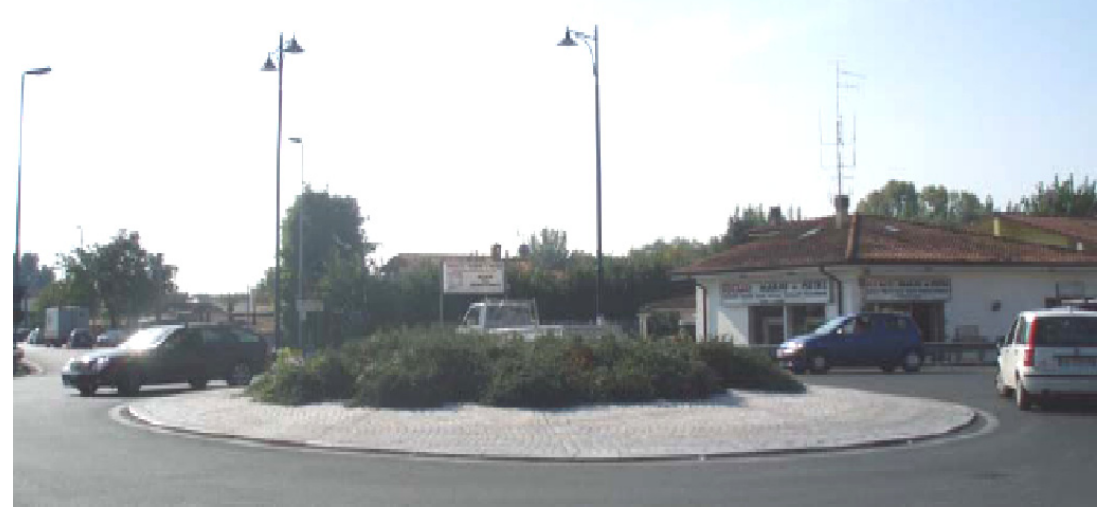

Figure 1: $\quad$ Reduced treatment.

b) Compressed treatment: Compressed treatment is defined as a feature of limited height and broad width, partly or wholly to occupy the space of the entire inner island. Features are more than 1.25 meters in height, and horizontal and vertical dimensions that are similar in dimension. It can be defined with a rectangular base ratio where width is not more than 1.5 times greater than the height. See Figure 2. 


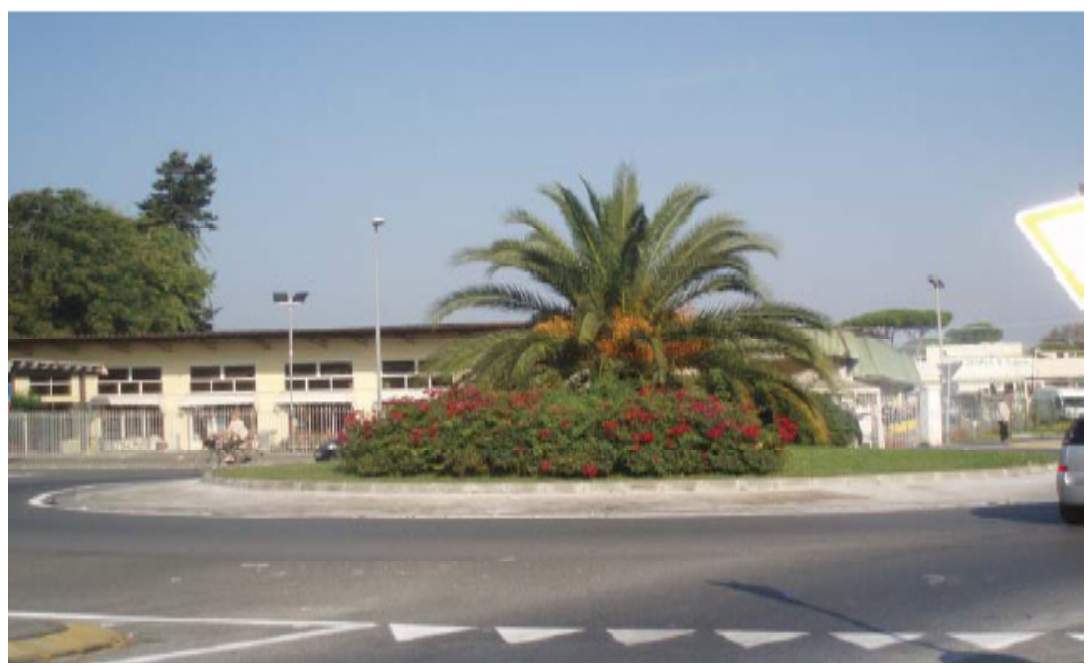

Figure 2: $\quad$ Compressed treatment.

c) Slender treatment: Slender treatments are designed with a prevalent central element, such as a tree with long trunk and few limbs (e.g., a palm), a tall sculpture or obelisk, a light pole, or advertizing totem - typically located in the centre of the island. We define slender where the diameter, $d$, of the inner island is more than five times greater than the base, $b$, of the treatment and where the height, $h$, of the treatment is at least three times the value $b$ of its base. See Figure 3 .

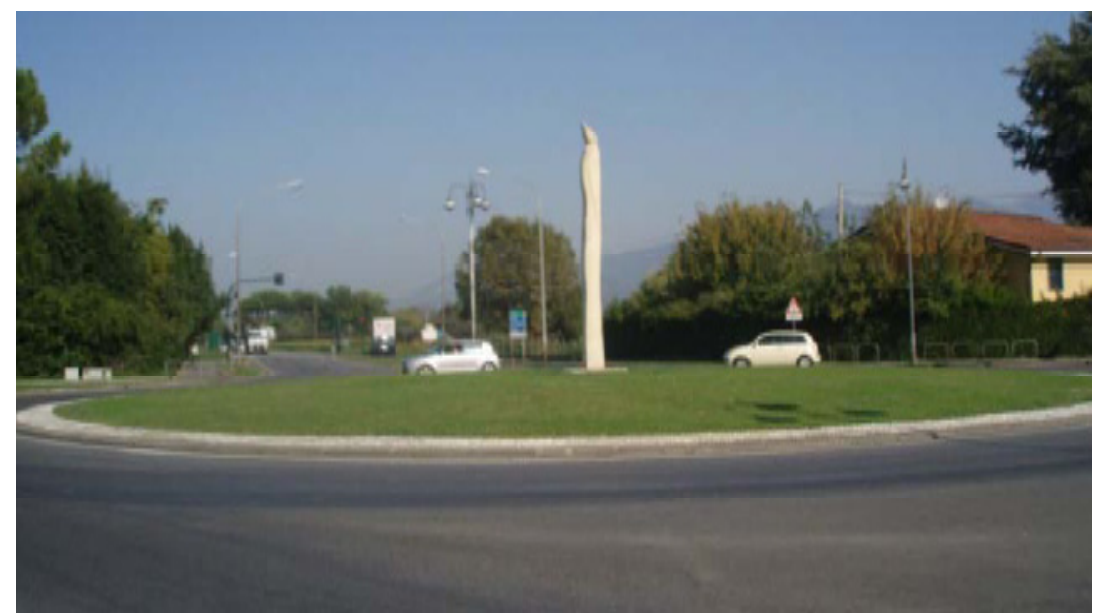

Figure 3: $\quad$ Slender treatment. 


\section{Data collection}

Data were collected with a laser rangefinder, model Leica A8, which has direct as well as indirect measurement capability to accurately measure lengths, areas and volumes [6]. Its laser rangefinder can used be up to distances of 100 meters. The instrument was positioned at each entrance of the roundabout at a distance of 15 meters from the circulating roadway delineating pavement markings at height of 1.25 meters. These values correspond to the minimum safe distance for clear perception of any yield controlled and average height of the eyes of a drive, in accordance with Italian guidelines [5]. Data on basic geometric characteristics of each roundabout were also collected, such as diameter of the outer inscribed circle, the central island diameter, width of the circulating roadway, and surface area of the central island treatment from the perspective of the approaching driver.

Figure 4 illustrates an example of the data collected at one of the study sites, while Table 1 summarizes the central island treatment type and solid angle data collected at each location in Italy.

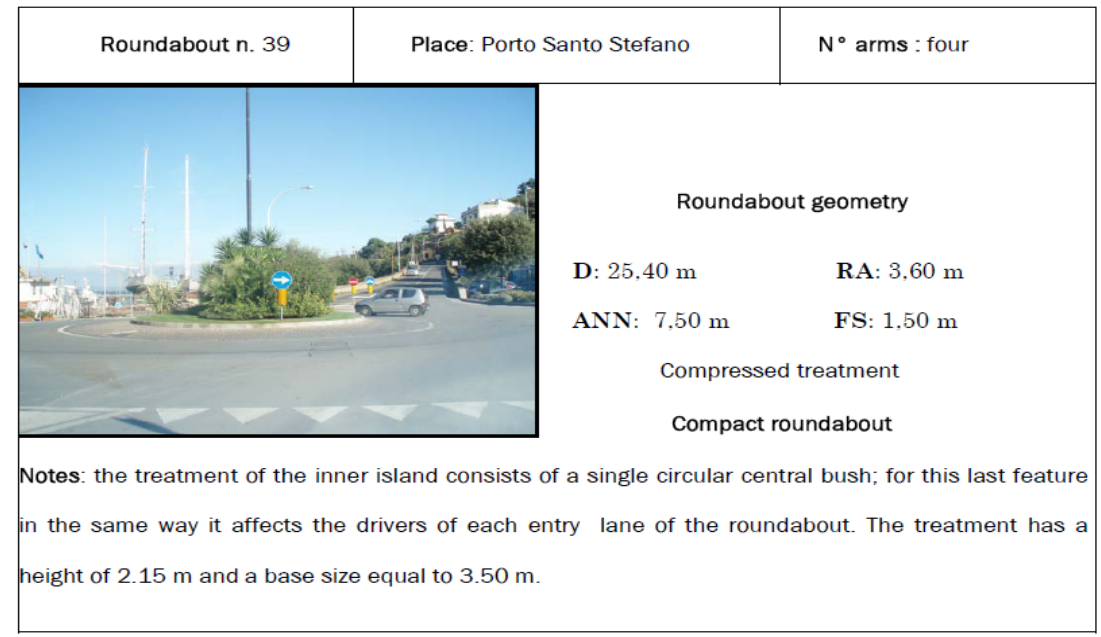

Figure 4: $\quad$ Example data collected.

\section{Analysis of solid angle data}

\subsection{Analysis of independence of central island treatment and roundabout type - Italian data}

Table 2 summarizes a descriptive statistical analysis of the solid angle data for Tuscan roundabouts by category of central island treatment type. The compressed treatment has the largest average solid angle, or visual intrusion, and is therefore assumed to provide the highest level of perceptibility for drivers approaching the roundabout. 
766 Sustainable Development and Planning V

Table 1: $\quad$ Summary of field data for forty roundabouts in Italy.

\begin{tabular}{|c|c|c|c|c|}
\hline $\begin{array}{l}\text { Roundabout } \\
\text { Number }\end{array}$ & $\begin{array}{c}\text { Roundabout } \\
\text { Type }\end{array}$ & $\begin{array}{c}\text { Treatment } \\
\text { Type }\end{array}$ & $\begin{array}{l}\text { Number of } \\
\text { Approaches }\end{array}$ & $\begin{array}{l}\text { Solid Angle Calculated For Each Approach } \\
\text { (steradians) }\end{array}$ \\
\hline 1 & 2 & 1 & 4 & $0.0036 ; 0.0030 ; 0.0036 ; 0.0030$ \\
\hline 2 & 2 & 3 & 4 & $0.0018 ; 0.0014 ; 0.0015 ; 0.0015$ \\
\hline 3 & 2 & 2 & 4 & $0.0019 ; 0.0013 ; 0.0014 ; 0.0018$ \\
\hline 4 & 3 & 2 & 3 & $0.0050 ; 0.0050 ; 0.0051$ \\
\hline 5 & 3 & 2 & 3 & $0.0030 ; 0.0030 ; 0.0030$ \\
\hline 6 & 3 & 2 & 4 & $0.0050 ; 0.0082 ; 0.0055 ; 0.0055$ \\
\hline 7 & 2 & 2 & 3 & $0.0061 ; 0.0061 ; 0.0061 ; 0.0061$ \\
\hline 8 & 3 & 1 & 3 & $0.0071 ; 0.0066 ; 0.015$ \\
\hline 9 & 3 & 2 & 3 & $0.0078 ; 0.0084 ; 0.0082$ \\
\hline 10 & 3 & 2 & 4 & $0.0090 ; 0.0088 ; 0.0092$ \\
\hline 11 & 2 & 1 & 3 & $0.0003 ; 0.0003 ; 0.0003$ \\
\hline 12 & 3 & 1 & 3 & $0.0010 ; 0.0010 ; 0.0010$ \\
\hline 13 & 3 & 2 & 4 & $0.0060 ; 0.0040 ; 0.0050 ; 0.0050$ \\
\hline 14 & 3 & 3 & 4 & $0.0062 ; 0.0062 ; 0.0062 ; 0.0062$ \\
\hline 15 & 3 & 2 & 4 & $0.0024 ; 0.0021 ; 0.0026 ; 0.0022$ \\
\hline 16 & 3 & 2 & 4 & $0.0009 ; 0.0003 ; 0.0010 ; 0.0004$ \\
\hline 17 & 2 & 3 & 3 & $0.0090 ; 0.0090 ; 0.0090$ \\
\hline 18 & 2 & 2 & 4 & $0.0035 ; 0.0033 ; 0.0030 ; 0.0033$ \\
\hline 19 & 2 & 3 & 3 & $0.0024 ; 0.0020 ; 0.0021$ \\
\hline 20 & 2 & 1 & 3 & $0.0057 ; 0.0057 ; 0.0057$ \\
\hline 21 & 2 & 1 & 4 & $0.0012 ; 0.0012 ; 0.0012 ; 0.0012$ \\
\hline 22 & 2 & 3 & 3 & $0.0018 ; 0.0014 ; 0.0016$ \\
\hline 23 & 3 & 3 & 3 & $0.0066 ; 0.0066 ; 0.0066$ \\
\hline 24 & 2 & 2 & 4 & $0.0081 ; 0.0077 ; 0.0081 ; 0.0077$ \\
\hline 25 & 2 & 2 & 4 & $0.0013 ; 0.0010 ; 0.0012 ; 0.0013$ \\
\hline 26 & 2 & 2 & 4 & $0.0012 ; 0.0009 ; 0.0010 ; 0.0010$ \\
\hline 27 & 3 & 2 & 4 & $0.0088 ; 0.0085 ; 0.0088 ; 0.0084$ \\
\hline 28 & 2 & 1 & 3 & $0.0042 ; 0.0039 ; 0.0042$ \\
\hline 29 & 2 & 1 & 4 & $0.0058 ; 0.0055 ; 0.0058 ; 0.0058$ \\
\hline 30 & 2 & 2 & 4 & $0.0016 ; 0.0016 ; 0.0016 ; 0.0016$ \\
\hline 31 & 3 & 2 & 4 & $0.0098 ; 0.0095 ; 0.0098 ; 0.0096$ \\
\hline 32 & 3 & 3 & 3 & $0.0060 ; 0.0060 ; 0.0060$ \\
\hline 33 & 2 & 3 & 3 & $0.0320 ; 0.0290 ; 0.0305$ \\
\hline 34 & 2 & 1 & 4 & $0.0029 ; 0.0025 ; 0.0025 ; 0.0027$ \\
\hline 35 & 2 & 3 & 4 & $0.0071 ; 0.0067 ; 0.0071 ; 0.0071$ \\
\hline 36 & 2 & 2 & 4 & $0.0120 ; 0.0120 ; 0.0120 ; 0.0120$ \\
\hline 37 & 2 & 3 & 4 & $0.00030 ; 0.00033 ; 0.00024 ; 0.00030$ \\
\hline 38 & 2 & 2 & 4 & $0.0047 ; 0.0051 ; 0.0045 ; 0.0045$ \\
\hline 39 & 2 & 2 & 4 & $0.0150 ; 0.0150 ; 0.0150 ; 0.0150$ \\
\hline 40 & 2 & 1 & 3 & $0.0062 ; 0.0062 ; 0.0062$ \\
\hline
\end{tabular}

LEGEND: Roundabout type: $1=$ mini roundabout; $2=$ compact roundabout; $3=$ large roundabout; Treatment Type: $1=$ reduced; $2=$ compressed; $3=$ slender 
Table 2: $\quad$ Summary of solid angle data by central island treatment, Italian data.

\begin{tabular}{|c|c|c|c|c|c|}
\hline $\begin{array}{c}\text { Central Island } \\
\text { Treatment Type }\end{array}$ & $\mathrm{N}$ & $\begin{array}{c}\mathrm{K}- \\
\text { Factor }\end{array}$ & $\begin{array}{c}\text { Solid Angle Mean } \\
\text { [steradians] }\end{array}$ & $\begin{array}{c}\text { Solid } \\
\text { Angle } \\
\text { Range }\end{array}$ & $\begin{array}{c}\text { Solid Angle } \\
\begin{array}{c}9 \% \text { Range } \\
\text { [steradians] }\end{array}\end{array}$ \\
\hline Reduced & 10 & 0.325 & 0.0039 & 0.0093 & $\begin{array}{c}0.0009 \div \\
0.0069\end{array}$ \\
\hline Compressed & 20 & 0.302 & 0.0058 & 0.0143 & $\begin{array}{c}0.0015 \div \\
0.0101\end{array}$ \\
\hline Slender & 10 & 0.325 & 0.0044 & 0.0087 & $0.0016 \div$ \\
& & & & & 0.0072 \\
\hline
\end{tabular}

$K$ is a dimensionless factor which, multiplied by the value of the range, gives the estimate of standard deviation from the normal range, i.e. the range that falls within $95 \%$ of the data collected [7].

Fisher's exact test is a test for the hypothesis test used in statistics in nonparametric situations with two nominal variables and small samples, named after its creator Ronald Fisher [8]. This test is used to check whether the data of two samples summarized in a $2 \times 2$ contingency table are consistent with the null hypothesis $\left(\mathrm{H}_{0}\right)$ that the populations of origin of the two samples have the same dichotomous division and that the observed differences with the data samples are due simply to chance. Let us introduce the meaning of some terms:

- Contingency table: a double entry table that is used in statistics to represent and analyze relationships between two or more variables.

- Dichotomous division: division of an entity into two mutually exclusive, such that it cannot be both simultaneously true and complete to each other.

In our case, we "cross" type of values and types of treatment of the inner island in order to find, for each test, if the sample distribution of cases is quite random $\left(\mathrm{H}_{0}\right.$ hypothesis) or whether the various treatment of central island belong to the same sample population $\left(\mathrm{H}_{1}\right.$ hypothesis). Since there are three island treatment types, we conduct three separate Fisher exact tests for each pair of treatment types, as follows for the Italian data.

Using the data presented in Table 3, we determine the p-value of Fisher test $=$ $12 \%$. As the percentage is higher than $5 \%$; we accept the null hypothesis $\mathrm{H}_{0}$ under which the two types of productions considered belong to different populations.

Table 3: $\quad$ Fisher exact test 1 - Italian data.

\begin{tabular}{|c|c|c|c|}
\hline & Large roundabouts & Compact roundabouts & Total \\
\hline Reduced treatment & 2 & 8 & 10 \\
\hline Compressed treatment & 10 & 10 & 20 \\
\hline Total & 12 & 18 & 30 \\
\hline
\end{tabular}


Using the data presented in Table 4, we determine the p-value of Fisher test $=$ $50 \%$. As the percentage is higher than 5\%; we accept the null hypothesis $\mathrm{H}_{0}$ under which the two types of productions considered belong to different populations.

Table 4: $\quad$ Fisher exact test 2 - Italian data.

\begin{tabular}{|c|c|c|c|}
\hline & Large roundabouts & Compact roundabouts & Total \\
\hline Reduced treatment & 2 & 8 & 10 \\
\hline Slender treatment & 3 & 7 & 10 \\
\hline Total & 5 & 15 & 20 \\
\hline
\end{tabular}

Using the data presented in Table 5, we determine the p-value of Fisher test $=$ $26 \%$. As the percentage is higher than $5 \%$; we accept the null hypothesis $\mathrm{H}_{0}$ under which the two types of productions considered belong to different populations.

Table 5: $\quad$ Fisher exact test 3 - Italian data.

\begin{tabular}{|c|c|c|c|}
\hline & $\begin{array}{c}\text { Large } \\
\text { roundabouts }\end{array}$ & $\begin{array}{c}\text { Compact } \\
\text { roundabouts }\end{array}$ & Total \\
\hline Slender treatment & 3 & 7 & 10 \\
\hline Compressed treatment & 10 & 10 & 10 \\
\hline Total & 13 & 17 & 30 \\
\hline
\end{tabular}

\subsection{Analysis of independence of central island treatment and roundabout type - U.S. data}

Solid angle data were also collected at forty-five locations in the United States. Summary statistics for the U.S. solid angle data are presented in Table 6 .

Table 6: $\quad$ Summary of solid angle data by central island treatment - U.S. data.

\begin{tabular}{|c|c|c|c|c|c|}
\hline $\begin{array}{c}\text { Central Island } \\
\text { Treatment Type }\end{array}$ & $\mathrm{N}$ & $\begin{array}{c}95 \% \text { Tolerance Interval } \\
(\lambda=.05) \\
\text { K-Factor }[9]\end{array}$ & $\begin{array}{c}\text { Solid Angle Mean } \\
\text { [steradians] }\end{array}$ & $\begin{array}{c}\text { Solid Angle } \\
\text { Standard } \\
\text { Deviation }\end{array}$ & $\begin{array}{c}\text { Solid Angle } 95 \% \\
\text { Tolerance Interval } \\
\text { [steradians] } \\
\text { (mean) }+ \text { or }-(\mathrm{k} * \mathrm{~s})\end{array}$ \\
\hline Reduced & 8 & 3.732 & .0113 & 0.0072 & zero to 0.0382 \\
\hline Compressed & 35 & 2.490 & .0278 & 0.0243 & zero to 0.0883 \\
\hline Slender & 2 & 37.674 & .0078 & 0.0006 & zero to 0.0304 \\
\hline
\end{tabular}

Fisher exact test analysis of the data collected in U.S. yields results that are consistent with the analysis of the data from Italy, and are presented as follows. 
Using the data presented in Table 7, we determine the p-value of Fisher test $=$ $11.3 \%$. As the percentage is higher than $5 \%$; we accept the null hypothesis $\mathrm{H}_{0}$ under which the two types of productions considered belong to different populations.

Table 7: $\quad$ Fisher exact test $1-$ U.S. data.

\begin{tabular}{|c|c|c|c|}
\hline & Large roundabouts & Compact roundabouts & Total \\
\hline Reduced treatment & 7 & 1 & 8 \\
\hline Compressed treatment & 20 & 15 & 35 \\
\hline Total & 27 & 16 & 43 \\
\hline
\end{tabular}

Using the data presented in Table 8, we determine the p-value of Fisher test $=$ $80 \%$. As the percentage is higher than $5 \%$; we accept the null hypothesis $\mathrm{H}_{0}$ under which the two types of productions considered belong to different populations.

Table 8: $\quad$ Fisher exact test $2-$ U.S. data.

\begin{tabular}{|c|c|c|c|}
\hline & Large roundabouts & Compact roundabouts & Total \\
\hline Reduced treatment & 7 & 1 & 8 \\
\hline Slender treatment & 2 & 0 & 2 \\
\hline Total & 9 & 1 & 10 \\
\hline
\end{tabular}

Table 9: $\quad$ Fisher exact test 3 - U.S. data.

\begin{tabular}{|c|c|c|c|}
\hline & Large roundabouts & Compact roundabouts & Total \\
\hline Slender treatment & 2 & 0 & 2 \\
\hline Compressed treatment & 20 & 15 & 35 \\
\hline Total & 22 & 15 & 37 \\
\hline
\end{tabular}

Fisher's Exact Test affirms that, as defined, the three treatments belong to different populations and therefore are independent from one another.

\subsection{Supplemental analysis of solid angle data - U.S. data}

Table 10 summarizes the solid angle estimates made from forty-five roundabout locations in the U.S. Since the data does not appear to be normally distributed, a non-parametric significance test for the difference of the mean solid angle between the three treatment groups - Reduced, Compressed, and Slender - is calculated. 
Table 10: Histogram of solid angle data - U.S. data.

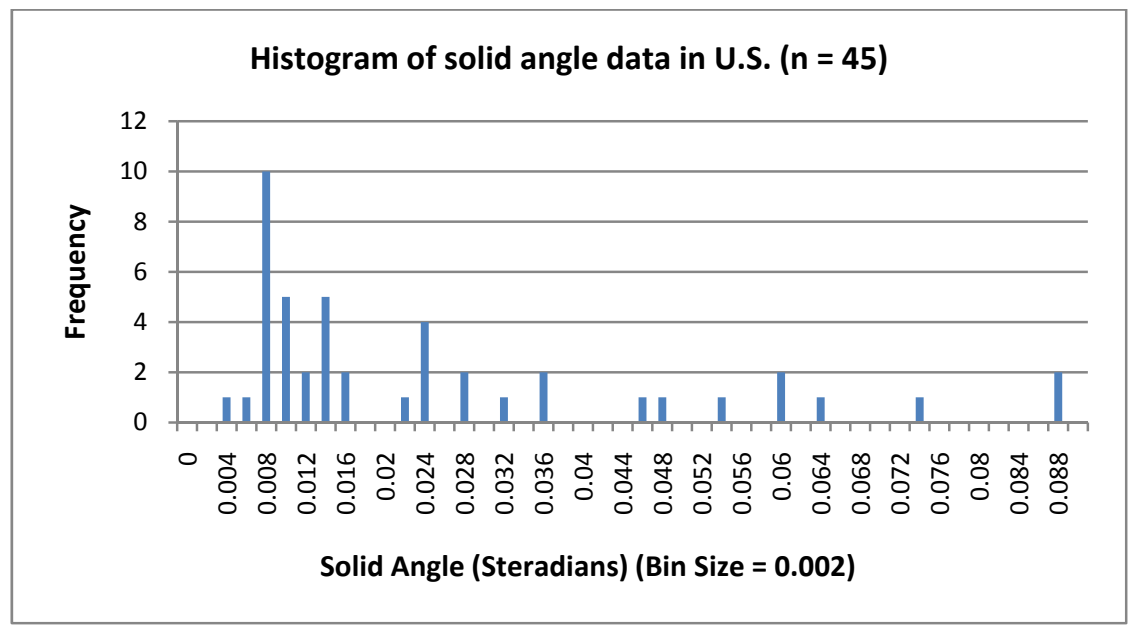

The Kruskal-Wallis [8] test yields the following:

- Null hypothesis: all three mean solid angles are the same.

- Alternative hypothesis: the three means are not equal.

- Alpha: $\alpha=0.05$.

- Chi-Square critical value (with $d f=2$ ): 5.991 .

- Calculated test statistic $h: 5.205$

Because $h$ does not fall in the critical region $(h<5.991)$, there is insufficient evidence at alpha-level $\alpha=0.05$ with the Kruskal-Wallis test to state that we reject the null hypothesis that the mean solid angles are all equal for the three central island treatment types. However, at an alpha-level of $\alpha=0.10$, the ChiSquare critical value (with $d f=2$ ) is equal to 4.605 , where we would reject the null hypothesis that the mean solid angles are all equal for the three central island treatment types $(h>4.065)$.

\section{Conclusions}

Previous work by the authors suggests that roundabouts characterized by a high value of solid angle are better perceived by approaching drivers [10]. The purpose of this paper was to begin to quantify this visibility as a function of central island treatment.

By Fisher's exact test we confirm that the classification of roundabouts by central island treatment is independent of size. We can distinguish between reduced, compressed and slender central island treatment, and that compressed treatment is generally more visible to the driver.

Future work could include development of an interactive website of roundabouts directory, similar to others existing in some European countries, 
such as the web page "Sens Giratoire" from France [9]. The intention would be to characterize engineering and agronomic features of roundabouts [10] in the region of concern.

\section{Acknowledgements}

The authors wish to thank the following individuals for their advice and contributions: Dr. Paolo Vernieri, Professor and Ms. Irene Bernardi, graduate student, Faculty of Agriculture, University of Pisa.

\section{References}

[1] Pratelli A. and Souleyrette R.R., Visibility, perception and roundabout safety, in Brebbia, C. (ed.) "Urban Transport XIV', Vol. 107, WIT Press. Ashurst Lodge 2009, pp. 577-588.

[2] Pratelli A., Souleyrette R.R. and Harding C., Roundabout perception: review of standards and guidelines for advanced warning, in Pratelli A. and Brebbia C. (eds.) "Urban Transport XV', Vol. 111, WIT Press, Ashurst Lodge 2010, pp. 71-82.

[3] Hopkinson, R.G., The evaluation of visual intrusion in transport situations, Traffic Engineering \& Control, Dec. 1972, pp. 387-395.

[4] Watkins T., The Concept of Solid Angle. Silicon Valley \& Tornado Alley, applet-magic.com, http://www.sjsu.edu/faculty/watkins/solidangle.htm.

[5] Italian Ministry of Facilities and Transport, Guidelines for the functional and geometric construction of intersection facilities, DM $\mathrm{N}^{\circ} 1699$, 19th April 2006.

[6] Falciani J., A roundabout classification model based on the inner island treatment. Laurea Thesis, Dept. of Civil Engineering, University of Pisa 2009.

[7] Crow E.L., Davis F. A. and Maxfield M.W., Statistics Manual, Dover Edition, New York 1960.

[8] Walpole R.E., Myers R.H., Myers S.L. and Ye K., Probability and Statistics for Engineers and Scientists, 8th Edition, Pearson International Ed., 2007.

[9] http://www.sens-giratoire.com.

[10] Vernieri P., The roundabout: an element in the urban landscape. in Vernieri P. (ed.) "Roundabouts: a visiting card for the environment, (in Italian) Felici Editore, Pisa 2008. 